\title{
The Generation of a Mesoscale Convective System from Mountain Convection
}

\author{
DONNA F. TUCKER \\ Department of Physics and Astronomy, University of Kansas, Lawrence, Kansas \\ N. ANDREW CROOK \\ National Center for Atmospheric Research Boulder, Colorado
}

(Manuscript received 18 November 1997, in final form 13 July 1998)

\section{ABSTRACT}

\begin{abstract}
A mesoscale convective system (MCS) that formed just to the east of Denver is investigated with a nonhydrostatic numerical model to determine which processes were important in its initiation. The MCS developed from outflow from previous convective activity in the Rocky Mountains to the west. Model results indicate that this outflow was necessary for the development of the MCS even though a convergence line was already present in the area where the MCS developed. A simulation with a 3-km grid spacing more fully resolves the convective activity in the mountains but the development of the MCS can be simulated with a 6.67-km grid. Cloud effects on solar radiation and ice sedimentation both influence the strength of the outflow from the mountain convection but only the ice sedimentation makes a significant impact on the development of the MCS after its initiation.

The frequent convective activity in the Rocky Mountains during the warm season provides outflow that would make MCS generation favorable in this region. Thus, there is a close connection between mountain convective activity and MCS generation. The implications of such a connection are discussed and possible directions of future research are indicated.
\end{abstract}

\section{Introduction}

Mesoscale convective systems (MCSs) commonly develop in the central United States during the warm season, accounting for $30 \%-70 \%$ of the summer precipitation (Fritsch et al. 1986). Maddox (1980) found that about half of the mesoscale convective complexes he studied had their initial storms near the eastern slopes of the Rocky Mountains. This preferred area for first storms is also apparent in the nocturnal MCSs examined by Augustine and Caracena (1994). In their study the initial storms of the larger MCSs were especially favored in this region. More MCSs form in this region than one would expect if the locations of their formation were random, and orographic processes appear to encourage their formation in some way. Nevertheless, MCSs also form in regions that are far from the mountains. Therefore, the conditions that encourage their formation are not unique to mountainous regions. Stensrud and Fritsch $(1993,1994)$ have indicated that MCSs will form only in a region in which the environmental conditions encourage upward motion on either the synoptic

Corresponding author address: Donna F. Tucker, Department of Physics and Astronomy, University of Kansas, Lawrence, KS 660452151.

E-mail: tucker@phoenix.phsx.ukans.edu scale or mesoscale. Forced lifting always occurs on the windward side of mountains; however, the mechanisms that promote lifting on the downwind side of mountains, where a large proportion of MCSs initiate, are not as obvious.

These observations have prompted investigators to examine the mechanisms that may contribute to the formation of an MCS downwind of mountains. Cotton et al. (1983) and McAnelly and Cotton (1986) presented evidence from observational data that orographic processes may form storms that go on to produce precipitation over the Great Plains. Tripoli and Cotton (1989) used a two-dimensional nonhydrostatic model to propose a mechanism by which an MCS could develop from mountain convection. They theorized that an MCS could begin when convective activity moved into a region with favorable upward motion brought about by both orographically produced gravity waves and thermally produced upslope flow.

Certainly the Rocky Mountains have been observed to be a very favorable area for thunderstorm development. The conditions described by Tripoli and Cotton (1989) would be present on most days during the warm season. Yet MCSs occur on only a minority of these days. Thus, additional factors must exist that control the development of MCSs but have greater variability from day to day. 


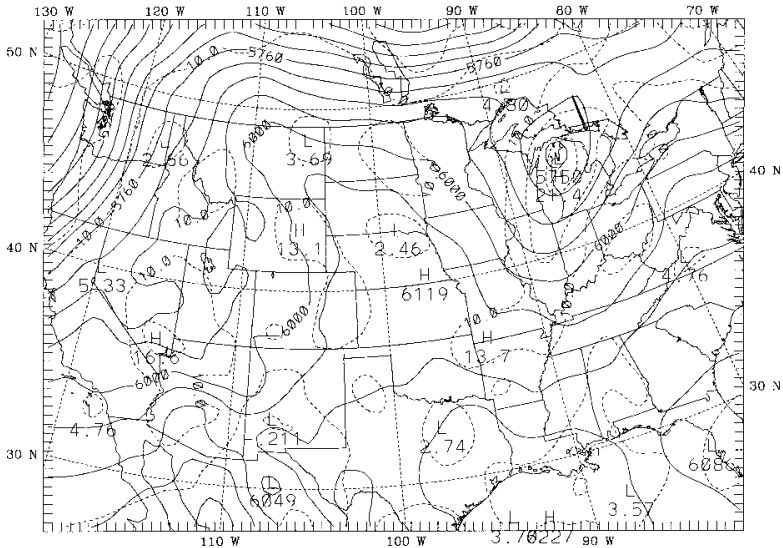

FIG. 1. 500-mb analysis for 1200 UTC 21 Jun 1993. Heights are contoured with solid lines every $60 \mathrm{gpm}$ and absolute vorticity $\left(\times 10^{-5}\right)$ is analyzed in dashed lines every $5 \mathrm{~s}^{-1}$.

This work employs a nonhydrostatic numerical model to examine a typical MCS that developed near the Front Range to gain insight into factors that would be especially favorable for MCS development in this region. Present computer capabilities are sufficient to allow a high resolution simulation in three dimensions. We will emphasize the initiation of the MCS and the factors affecting the initiation process. Single-celled thunderstorms may develop in an unorganized fashion but multiple-celled storms usually require a well-defined generation mechanism. An outflow boundary from previous convection often serves this purpose and we will focus on this process herein. We will not be stressing details of the system structure nor its subsequent development. The particular case chosen will be described in section 2 and a brief description of the numerical model will be given in section 3 . Section 4 describes the initial convective development in the mountains and factors that control the strength of the convection and its outflow. The actual generation of the MCS on the plains near the mountains is the subject of section 5. Section 6 will consist of conclusions and a summary.

\section{Case study description}

The event we are considering occurred in eastern Colorado on 21 June 1993. Typical summertime conditions are present in this region with fairly weak synoptic-scale forcing. The 500-hPa analysis, shown in Fig. 1, reveals only moderate amounts of vorticity for a middle-latitude location with a maximum located in central Wyoming. There is a negatively tilted ridge in the central United States. This feature has been associated with heavy precipitation in the western United States (Maddox et al. 1980) but the precipitation that fell in this case was not heavy.

Although the Denver sounding at 1200 UTC (Fig. 2) has weak winds in the middle to upper troposphere, it does not appear to have enough moisture to support

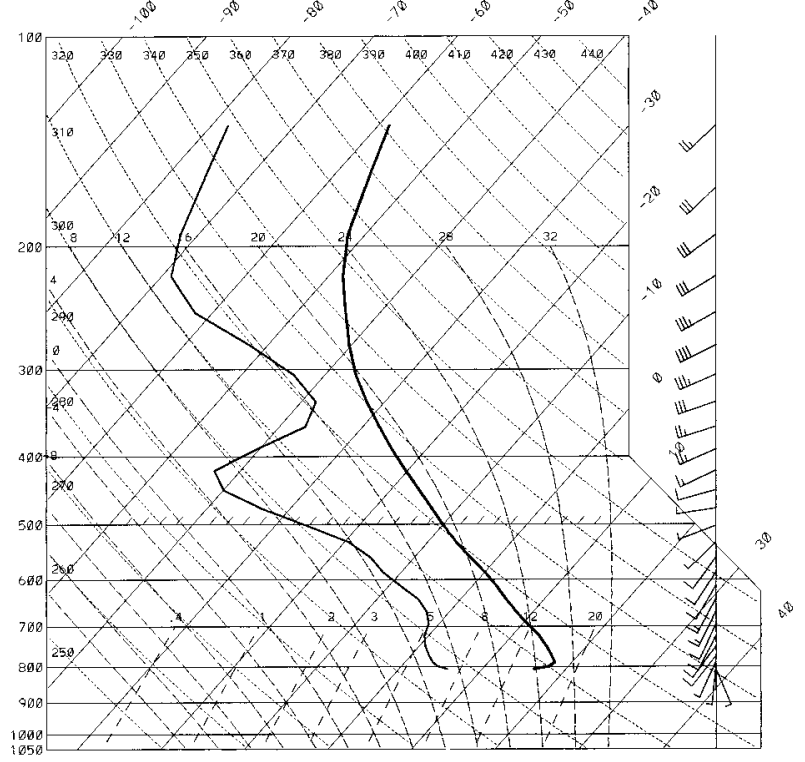

FIG. 2. Skew $T-\log p$ diagram for Denver sounding at 1200 UTC 21 Jun 1993. Full wind barb is $5 \mathrm{~m} \mathrm{~s}^{-1}$.

heavy precipitation. The total precipitable water is 1.64 $\mathrm{cm}$, which is $106 \%$ of the normal June average. Flash flood-producing storms in this region, which occur under similar conditions, normally have precipitable water contents of $2.4 \mathrm{~cm}$ or greater (Maddox et al. 1980). The highest relative humidity is near $350 \mathrm{hPa}$, a very high altitude even for a High Plains sounding. There are some changes in the shear profile between 750 and $650 \mathrm{hPa}$, but the winds are very weak in that layer and in most

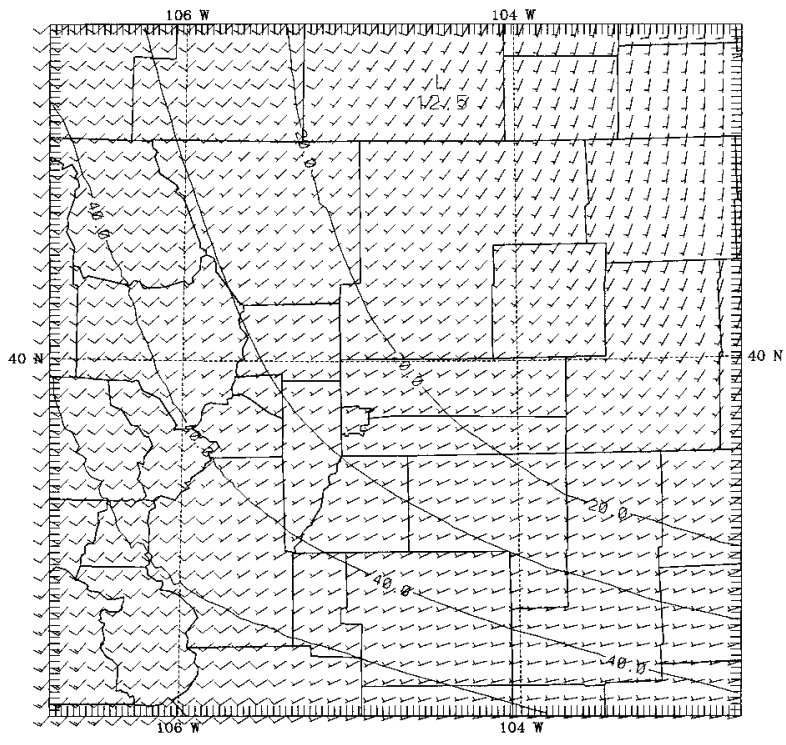

FIG. 3. 500-mb observed relative humidity and winds for 1200 UTC 21 Jun 1993 over innermost grid region shown in Fig. 5. Relative humidity is contoured every $10 \%$, with full wind barb representing $5 \mathrm{~m} \mathrm{~s}^{-1}$. Denver County is the smallest county near the center of the map. 


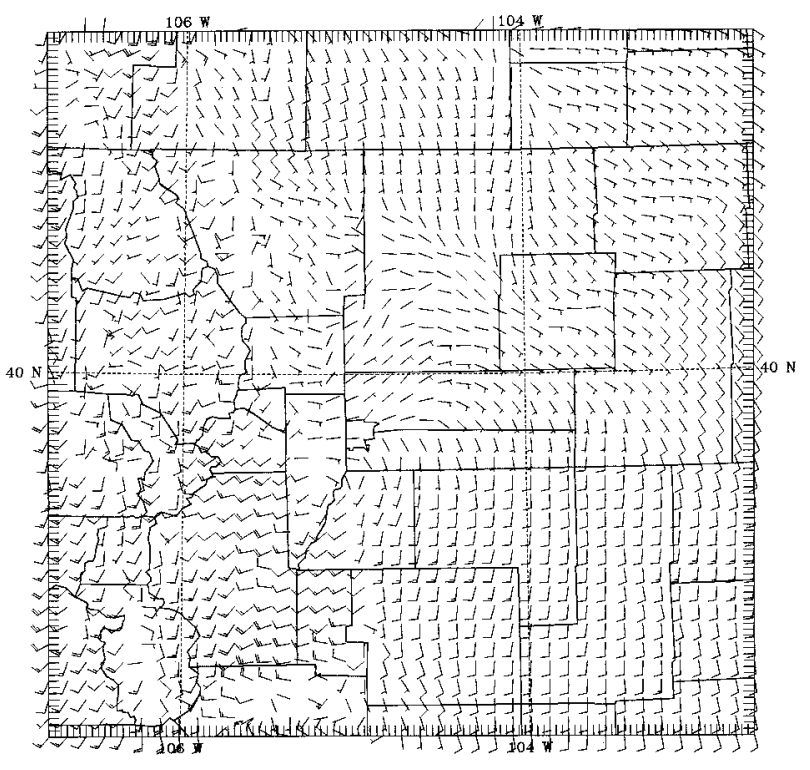

FIG. 4. Model forecast winds (full wind barb is $5 \mathrm{~m} \mathrm{~s}^{-1}$ ) at the lowest sigma level of $\sigma=0.995$. Forecast is valid 1600 UTC 21 Jun 1993.

of the sounding the shear is primarily unidirectional, which would favor the development of multicellular storms. The surface inversion is quite shallow and would be broken very early in the day. Although the humidity at $500 \mathrm{hPa}$ is small, Fig. 3 shows that the relative humidity gradient is quite large and oriented almost parallel to the winds. The 500-hPa level has strong moisture advection over the eastern plains of Colorado with a representative value of $1.5 \times 10^{-5} \mathrm{~g} \mathrm{~kg}^{-1} \mathrm{~s}^{-1}$. For comparison, values of moisture advection in this area at 600 and $700 \mathrm{mb}$ are $5.6 \times 10^{-6} \mathrm{~g} \mathrm{~kg}^{-1} \mathrm{~s}^{-1}$ and $3.4 \times 10^{-5}$ $\mathrm{g} \mathrm{kg}^{-1} \mathrm{~s}^{-1}$, respectively. Thus, there is moderately strong moisture advection at $500 \mathrm{hPa}$ despite the weak winds. Note that these values are those at an instantaneous time

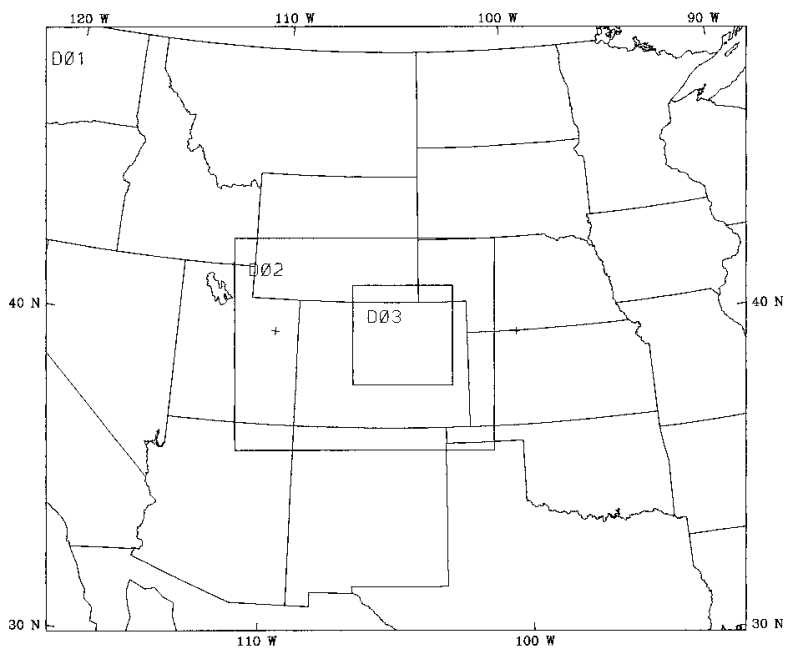

FIG. 5. Locations of the nested grids.
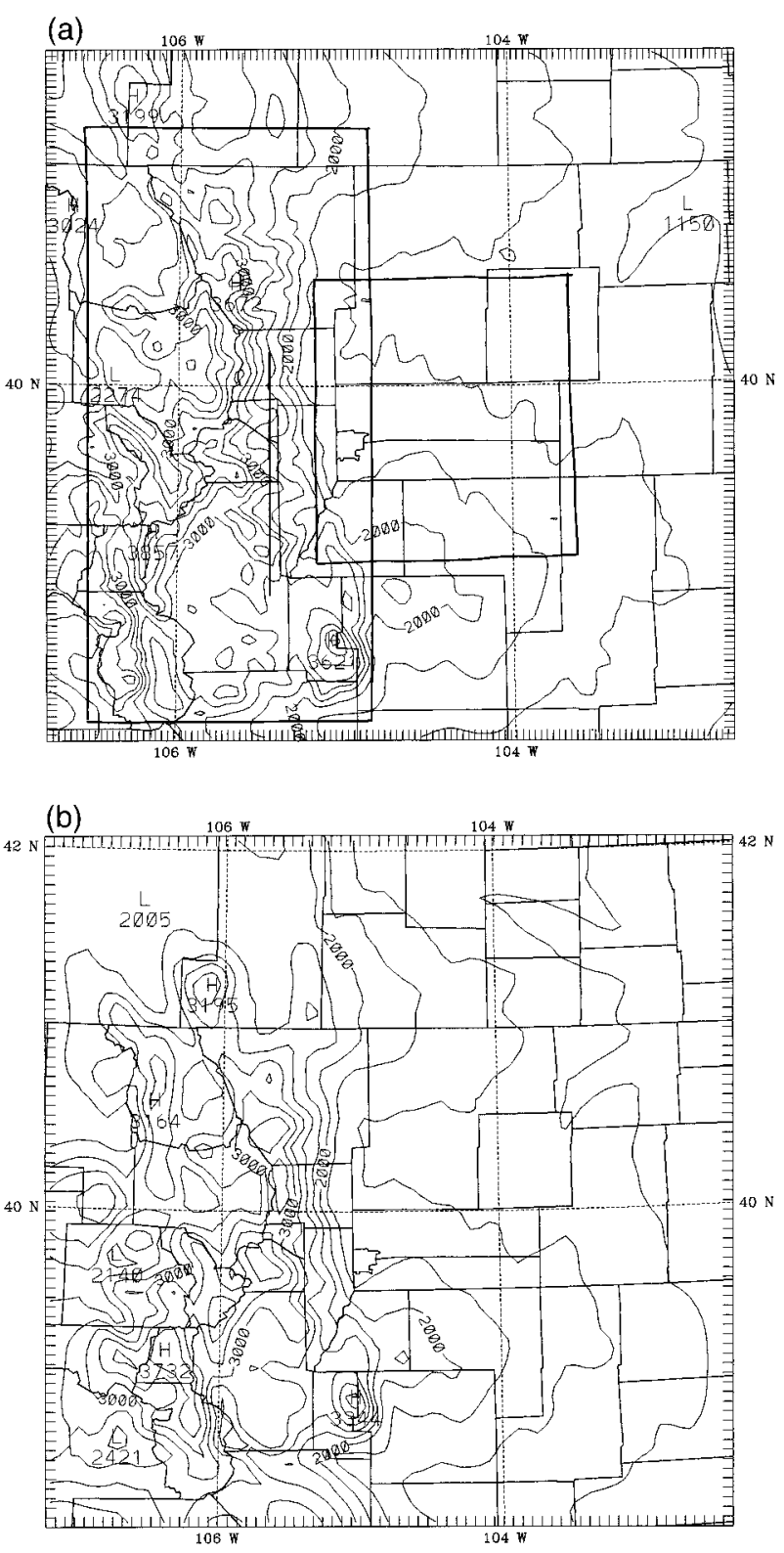

FIG. 6. Model terrain on the innermost grid. Contours are drawn every $250 \mathrm{~m}$ : (a) $3-\mathrm{km}$ grid. The western box represents the mountain analysis domain and the eastern box represents the plains analysis domain. The line along which the cross section is taken is given by the thick line within the western box: (b) $6.67-\mathrm{km}$ grid.

when the moisture gradient was fairly strong. They do not necessarily represent the magnitude of the moisture advection throughout the day.

It is also significant to note that the Denver Convergence-Vorticity Zone (DCVZ; Szoke et al. 1984) was present on this day. This feature has been associated with tornadic development in the Denver area but no tornadoes were reported in Colorado on this day. Although the initial data for the model do not allow the DCVZ to be resolved, the model develops it very early in the simulation (Fig. 4). As will be shown, the de- 
TABle 1. Summary of sensitivity experiments.

\begin{tabular}{|c|c|}
\hline Name & Description \\
\hline CONTROL & As described in section 3 \\
\hline NOEVAPCOOL & $\begin{array}{l}\text { Does not include the cooling effects of evaporation } \\
\text { of falling hydrometeors }\end{array}$ \\
\hline NOCLOUD & Does not include the radiative effects of clouds \\
\hline NOSED & Does not include ice sedimentation \\
\hline LOWRES & Larger grid spacing than CONTROL \\
\hline
\end{tabular}

velopment of convergence in the Denver region is important for the subsequent generation of the MCS.

\section{Model description}

The model chosen for this study is the nonhydrostatic version of the Pennsylvania State University-National

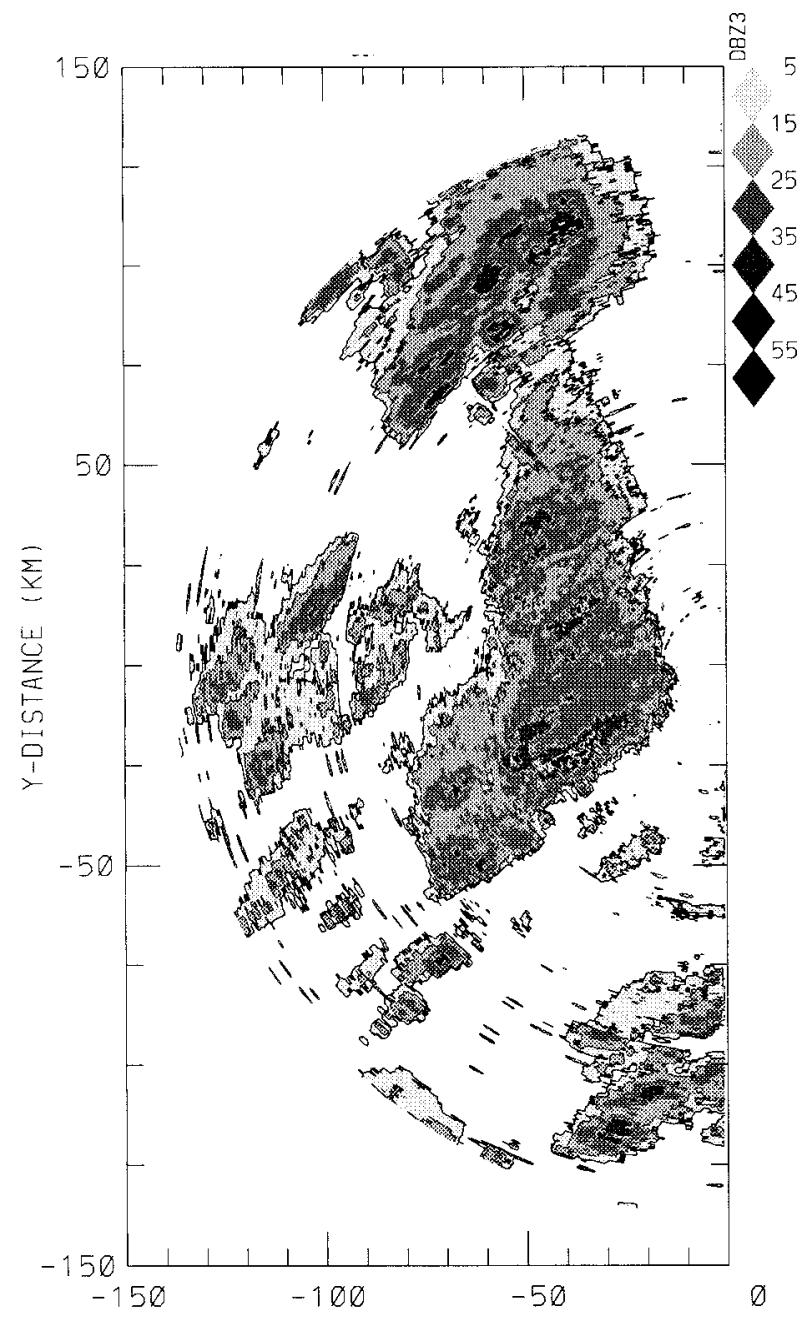

FIG. 7. Depiction of the mountain convection as observed by Mile High Radar (MHR) in the mountain domain shown in Fig. 6. Maximum reflectivity at each point in the horizontal between 1700 and 1900 UTC and above $Z=4 \mathrm{~km}$ mean sea level is shown. The lower altitude cutoff is chosen to avoid ground clutter from the mountains. Domain of the figure is shown by the heavy outline in Fig. 8 .
Center for Atmospheric Research Mesoscale Model version 5.2 (MM5V2; Dudhia 1993). It uses a terrain-following vertical coordinate system with $\sigma_{p}$ defined by

$$
\sigma_{p}=\frac{p_{0}(z)-p_{t}}{p_{0}\left(z_{s}\right)-p_{t}},
$$

where $p_{0}$ is a reference pressure that depends only on height above sea level, $p_{t}$ is the pressure at the top of the model, and $z_{s}$ is the height of the earth's surface.

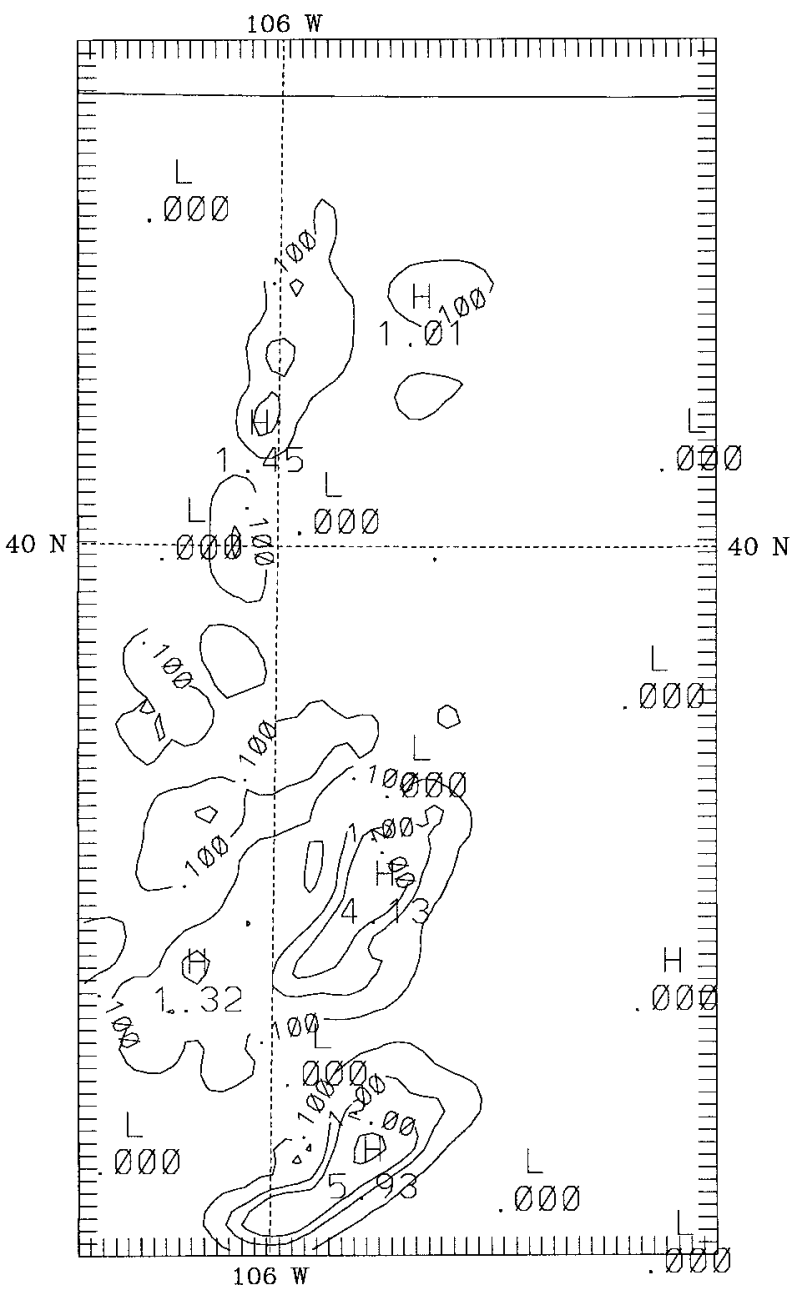

FIG. 8. Model-accumulated precipitation on the 3-km grid for 1200 UTC through 1900 UTC. Contours are at 0.1, 1.0, 2.0, 5.0, and 10.0 $\mathrm{mm}$. Domain corresponds to that of the radar image in Fig. 7. 


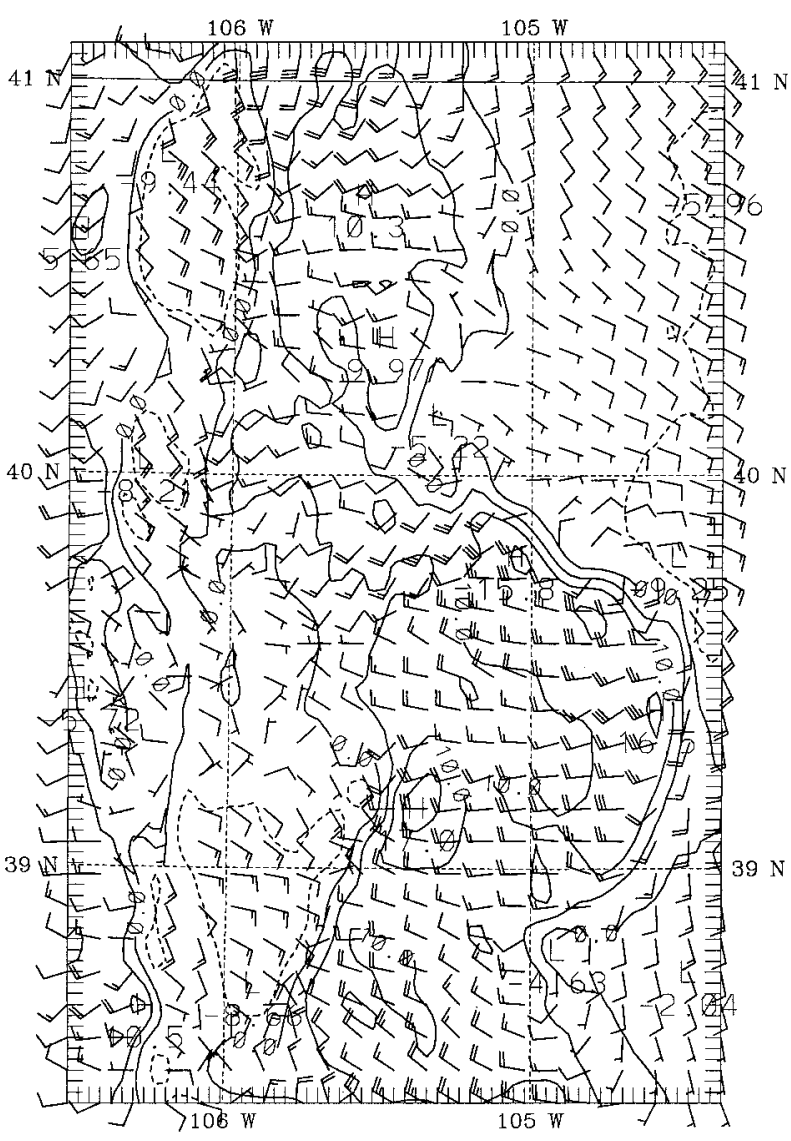

FIG. 9. Winds predicted on the $3-\mathrm{km}$ grid at the lowest model level $(\sigma=0.995)$ at 2000 UTC. The contour interval on east-west velocity component is $5 \mathrm{~m} \mathrm{~s}^{-1}$ and negative values are dashed. Wind barbs are given every third grid point with a full barb representing $5 \mathrm{~m}$ $\mathrm{s}^{-1}$. Domain is $30 \mathrm{~km}$ wider (extended to the east) than that of the radar image in Fig. 7.

The following sections summarize the particular model configurations used in this work.

\section{a. Nested grids}

In all simulations, two-way interactive nested grids with 27 vertical layers are adopted. The model top is defined to be at $100 \mathrm{hPa}$. Three grids are defined, the outermost of which has fixed boundaries. For most simulations the coarsest grid had a spacing of $27 \mathrm{~km}$, the middle grid $9 \mathrm{~km}$, and the finest grid $3 \mathrm{~km}$. The number of grid points in each of these domains was $90 \times 75$, $100 \times 80$, and $115 \times 115$, respectively. The geographic locations for these grids can be seen in Fig. 5. The locations of the two inner grids are far enough away from the boundary of the outer grid that they would not be affected by the values at the outer boundary in a 12-h period. Weisman et al. (1997) found that the accuracy of the representation of mesoscale systems by a numerical model deteriorates significantly at grid resolutions larger than $4 \mathrm{~km}$. For this reason, the effect of

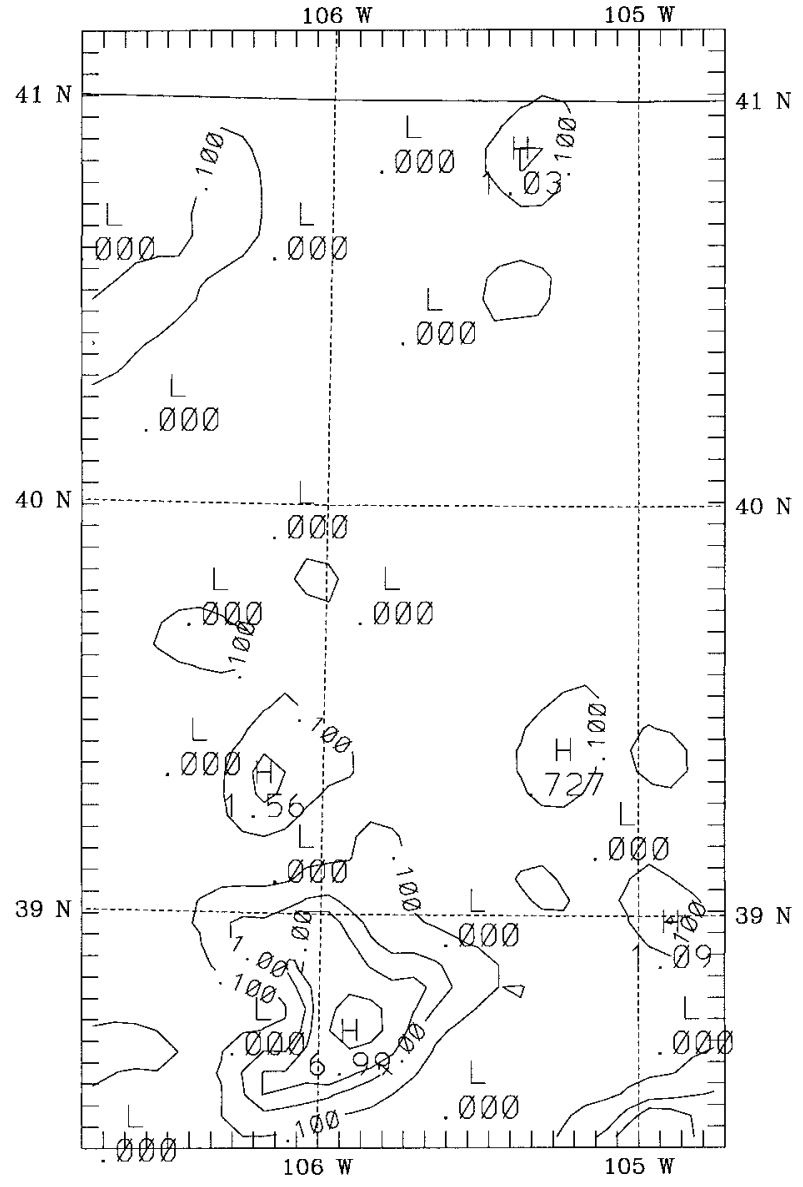

FIG. 10. As in Fig. 8 except for the larger $6.67-\mathrm{km}$ grid (LOWRES).

resolution was examined with a series of grids with larger grid spacings. For this low-resolution version the coarse grid had a spacing of $60 \mathrm{~km}$, the middle grid 20 $\mathrm{km}$, and the finest grid $6.67 \mathrm{~km}$. The number of grid points in each domain was $58 \times 79,61 \times 79$, and 73 $\times 73$, respectively. Their geographic locations are comparable to those in Fig. 5. A comparison of the surface elevations on the smallest grid at both resolutions can be seen in Figs. 6a,b. Generally the major difference between the two is that the higher-resolution topography has higher surface elevations in the mountains.

\section{b. Model physics}

The model uses a high-resolution planetary boundary layer parameterization (Blackadar 1976, 1979; Zhang and Anthes 1982). Surface characteristics are varied by designating each grid point to be represented by one of several land use types. In most simulations, shortwave and downward longwave radiation are influenced by the effect of parameterized cloud cover. Although diffusion in MM5V2 is frequently based on the perturbation temperature rather than the actual temperature, we used the 


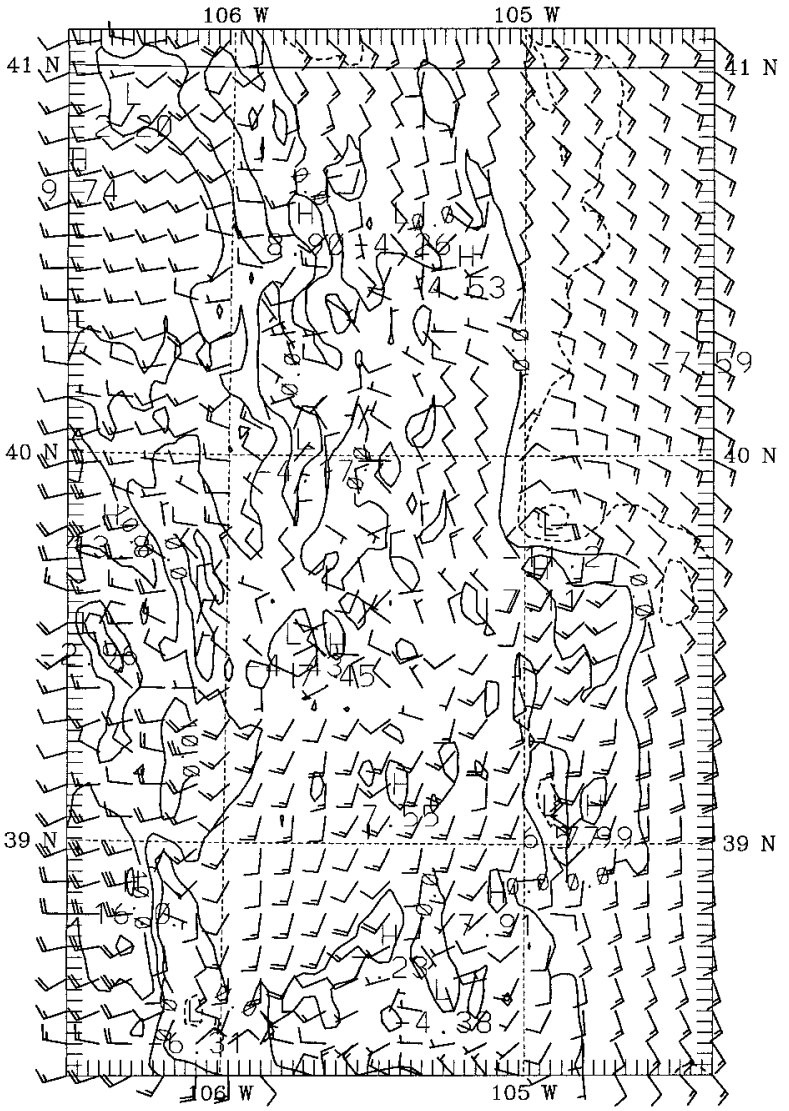

FIG. 11. As in Fig. 9 except from simulation, which does not include evaporative cooling (NOEVAPCOOL).

actual temperature for diffusion. The diffusion coefficient is doubled for all variables on the fine grid to help control instabilities that develop at this resolution.

An explicit precipitation scheme is used on all three grids while a convective parameterization developed by Grell (1993) is used on the two largest grids. The explicit scheme includes the ice phase above the freezing level but not supercooled water. Within this restriction all types of phase changes for water are included.

\section{c. Initialization}

This work follows the procedure most commonly used with the initialization of the MM5 model. Constant pressure-level data from the National Center for Environmental Prediction global analysis (the analysis on which the global spectral model runs are based) are used for the first-guess field. These values at the grid points are adjusted based on standard rawinsonde and surface data. This adjustment allows features to be included in the model initial fields that cannot be resolved by the global model grid. Neither nonstandard upper air and surface data, nor data from special field programs are used in the initial fields. The values are interpolated to the model sigma surfaces and the mean divergence in the column is removed. All simulations begin at 1200 UTC 21 June 1993 (0600 local time).

\section{Mountain convection and outflow}

The simulation using the model parameters as described above will be known as the control. A brief description of the sensitivity studies that have been performed is presented in Table 1. If not otherwise specified, discussion refers to the control run of the model.

\section{a. Comparison of observed and modeled convective development}

Observations from Mile High Radar (MHR), located $20 \mathrm{~km}$ northeast of Denver, indicate that convective activity is well under way along the Front Range at 1900 UTC (Fig. 7). The timing of this development is representative of that which commonly occurs in this region and season. The control simulation also shows large amounts of convective activity in this general region by 1900 UTC (Fig. 8) although precipitation is slightly to the west of that indicated by the radar. It should be kept in mind that radar echos above the mountains are primarily from the higher tilts of the radar $\left(5.5^{\circ}\right.$ and greater). Thus the radar may not be able to detect all the precipitating storms in this region. Likewise, some of the precipitation in the model simulation is out of range of the radar. The control simulation also has precipitation maxima at $40.5^{\circ} \mathrm{N}, 106.0^{\circ} \mathrm{W}$ and $40.0^{\circ} \mathrm{N}$, $105.8^{\circ} \mathrm{W}$. Although these are too far from the radar to be detected by the $5.5^{\circ}$ tilt, there is some evidence for these precipitation areas at the lower tilts $\left(2.5^{\circ}\right.$ and $4.0^{\circ}$, not shown) even though radar returns at these tilts are heavily contaminated by ground clutter. Strong outflow occurs from the modeled cells at about $41.0^{\circ} \mathrm{N}, 106.0^{\circ} \mathrm{W}$ and especially around $39.3^{\circ} \mathrm{N}, 104.8^{\circ} \mathrm{W}$ (Fig. 9). We quantify the strength of the outflow by both the maximum east-west component and the maximum wind speed. In this second area the outflow has a maximum westerly component/maximum wind speed of $16.5 \mathrm{~m}$ $\mathrm{s}^{-1} / 18.0 \mathrm{~m} \mathrm{~s}^{-1}$. The leading edge of the outflow shows up well in the strong gradients of the east-west wind component ahead of these positions. Since the outflow has a large component parallel to the radar beam, it can be seen in the Doppler velocities from MHR as well (not shown).

The simulation with lower resolution (LOWRES) has only minimal precipitation in the mountains (Fig. 10). LOWRES still does have precipitation at $38.8^{\circ} \mathrm{N}$, $106.0^{\circ} \mathrm{W}$ and the outflow from this cell is quite strong. The lower resolution will not only affect the numerical solution but also the resolution of the topography. This comparison shows that sufficient resolution is important in order to properly simulate mountain convection. 

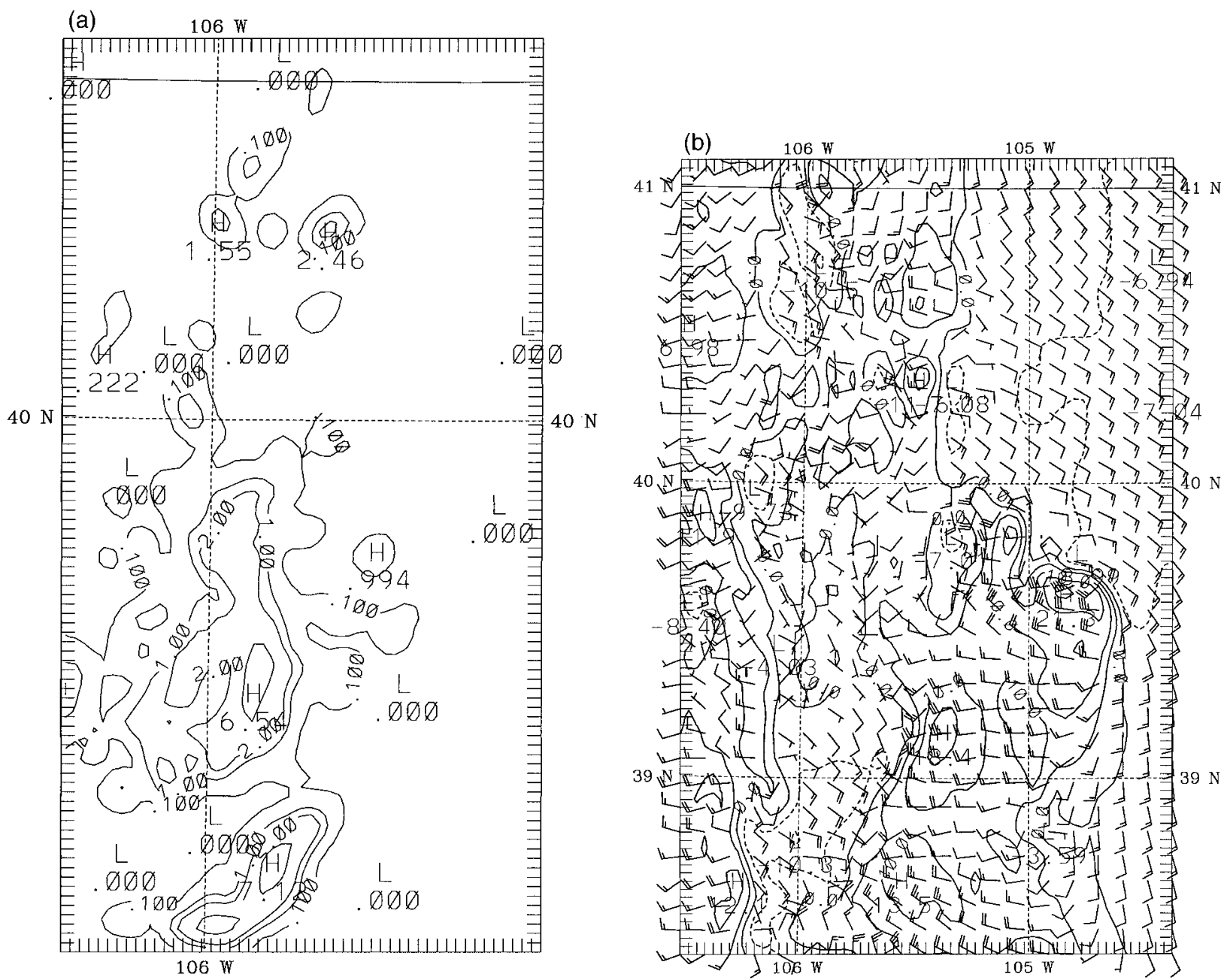

FIG. 12. (a) As in Fig. 8 except for the simulation that does not include the effects of clouds on solar radiation (NOCLOUD). (b) As in Fig. 9 except for the simulation NOCLOUD.

\section{b. Factors affecting outflow strength}

Strong near-surface winds close to the thunderstorm are outflow generated by negatively buoyant air as it reaches the earth's surface. This negative buoyancy would largely be the result of evaporation of falling hydrometeors. Indeed in the NOEVAPCOOL simulation in which evaporative cooling is turned off, winds of similar strength to the control do not appear (Fig. 11) confirming that their generation is highly dependent on evaporative processes. The outflow has a maximum westerly wind component/maximum wind speed of 8.0 $\mathrm{m} \mathrm{s}^{-1} / 12.0 \mathrm{~m} \mathrm{~s}^{-1}$ (compared with $16.5 \mathrm{~m} \mathrm{~s}^{-1} / 18.0 \mathrm{~m}$ $\mathrm{s}^{-1}$ in the control). Note that in this simulation rain still evaporates but does not cool the air. Thus, it is interesting that the precipitation in the mountains is much higher when evaporative cooling is removed. We believe that the most likely explanation of this phenomenon is that without this cooling the low-level air is more positively buoyant, rises higher and faster, and generates more precipitation. Indeed, temperatures in the lower layers of the model are about $1{ }^{\circ} \mathrm{C}$ higher for the NOEVAPCOOL simulation at the time precipitation is falling and middle level vertical velocities are higher. It is also possible that the lack of outflow enables the storms to have longer lifetimes since they are able to stay closer to their initiation point. With longer lifetimes, the individual storms produce more precipitation.

MM5V2 does show that the thunderstorm outflow is sensitive to several parameters. Thermally induced upslope flow has been shown to be sensitive to cloud shading (Segal et al. 1986). If the reflection of solar radiation by clouds is not included in the model physics (experiment NOCLOUD), more precipitation is produced and the outflow from the convection is stronger (Fig. (Fig. 12). The outflow has a maximum westerly wind component/maximum wind speed of $21.3 \mathrm{~m} \mathrm{~s}^{-1} / 21.3 \mathrm{~m} \mathrm{~s}^{-1}$ (compared with $16.5 \mathrm{~m} \mathrm{~s}^{-1} / 18.0 \mathrm{~m} \mathrm{~s}^{-1}$ in the control). This increase is caused by higher temperatures at the earth's surface as a result of more solar radiation reaching the ground. Figure 13 shows that higher tempera- 


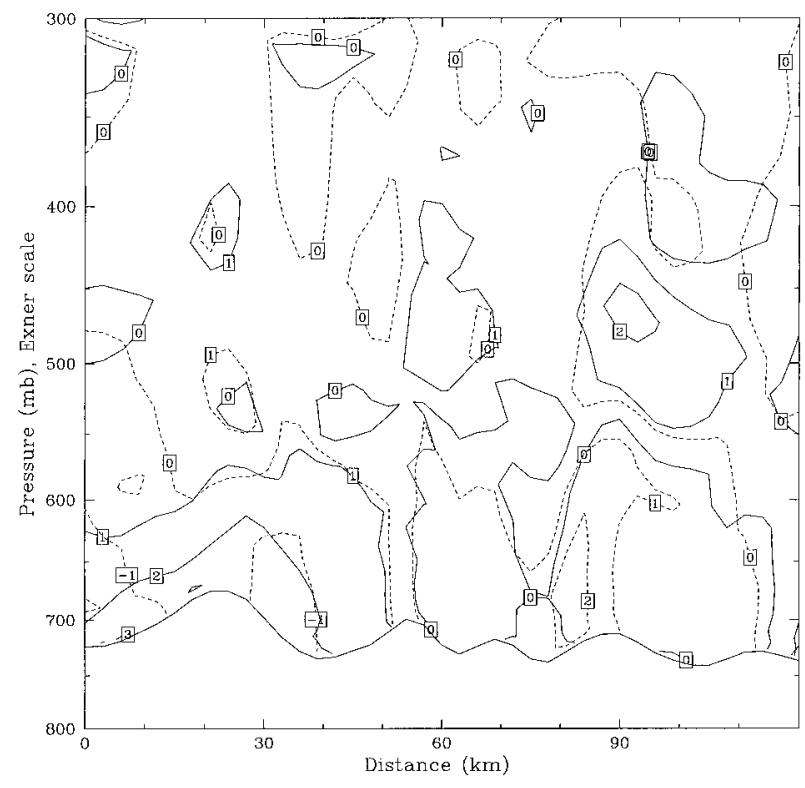

FIG. 13. Vertical cross section valid at 1800 UTC 21 Jun 1993 along the line shown in Fig. 6a. Solid contours represent the difference in the potential temperature in Kelvins between the model run, which did not include the effects of clouds on solar radiation, and the one that did include the effects of clouds on solar radiation. Dashed lines depict the same difference in mixing ratios in $10^{-1} \mathrm{~g} \mathrm{~kg}^{-1}$.

tures and humidity near the earth's surface in the mountains occur with the NOCLOUD simulation. These conditions would encourage the development of deeper convective storms with more evaporation near the earth's surface. It also shows the cold outflow concentrated in the valleys and this process is further advanced in the NOCLOUD simulation. It is possible that the valleys act to funnel and strengthen the outflow in some situations.

Simulation NOCLOUD had shown that in this case cloud shading effects result in weaker storms and reduced outflow. These results contrast with those of Koch (1984), who found that cloud shading could increase convective strength by enhancing a mesoscale circulation forced by variations in surface sensible heating. Our case is different, however, in that it does not occur in the presence of a frontal system or any strong horizontal temperature gradient. In addition, the cloud cover in our case is fairly widespread and does not have sharp gradients to generate a mesoscale circulation.

The model also indicates that ice sedimentation plays an important role in strengthening the convective outflow. Ice sedimentation was added to the explicit precipitation scheme at the time MM5 version 2 was released. If this process is not included in the model (simulation NOSED), the precipitation amounts in the mountains are lower and the outflow is noticeably weaker (Fig. 14). The outflow has a maximum westerly wind component/maximum wind speed of $14.2 \mathrm{~m} \mathrm{~s}^{-1} / 14.4 \mathrm{~m}$ $\mathrm{s}^{-1}$. The falling ice provides the lower layers with a supply of developed hydrometeors. Although the model does not include mixed phases in the precipitation representation, the falling of ice crystals from higher levels still enables the clouds to produce more raindrops. This process emphasizes the importance of the ice process and of the need for high relative humidities at upper levels to produce sufficient ice crystals. Recall that in the initial fields for this case, the relative humidities were highest at $350 \mathrm{mb}$. Tripoli and Cotton (1985) pointed out the importance of moisture flow from the southwest for MCS development in this region. Due to the high terrain, such moisture flow would occur mainly at middle and upper levels in the troposphere. The present work suggests that high moisture at these levels is important not only to encourage the development of deep convection but also to help to produce sufficient number of ice crystals to strengthen the storm's outflow.

\section{Generation and propagation of MCS}

Radar shows a convergence line has developed just east of the Denver area at about 2000 UTC (Fig. 15a). A couple of small cells can be seen south of the MHR but no widespread convection is taking place on the plains at this time. The model shows that the outflow from the convective activity in the mountains was just reaching the plains at this time (Fig. 9). An hour later the radar shows that convective cells have developed all along this convergence line. Thus, there was a precipitation minimum in the region between the mountains and the convergence line. This feature indicates that the outflow from the mountain convection itself was not strong enough to generate precipitating convection until it reached the convergence line where a sufficient amount of convergence to initiate thunderstorms was generated. Moist convection first initiated at the southern end of the convergence line where the outflow from the mountain convection was the strongest. The model initiates this area of convection but is slow to propagate the storms northward (Fig. 16a). The model shows the later propagation of these cells both northward and eastward (Fig. 16b). Outflow remains strong (Fig. 17) and aids the propagation of this system of convective cells. Outflow tends to be stronger on the north side of the system because the environmental flow in this region is generally from the south and therefore results in increased winds where the outflow direction is southerly.

The gradient of convective inhibition (CIN) across this region before the convection initiates is from north to south (Fig. 18). The smaller values in the southern part of the domain would make this region a preferable one for the MCS to initiate. The strongest outflow from the mountain thunderstorms occurs in the region of smallest CIN. The MCS propagates northward into a region with larger CIN values. Thus, the northward propagation of the MCS occurs because of the strong outflow of the storms to the north rather than the more favorable environment.

Estimates of the precipitation amounts from this con- 

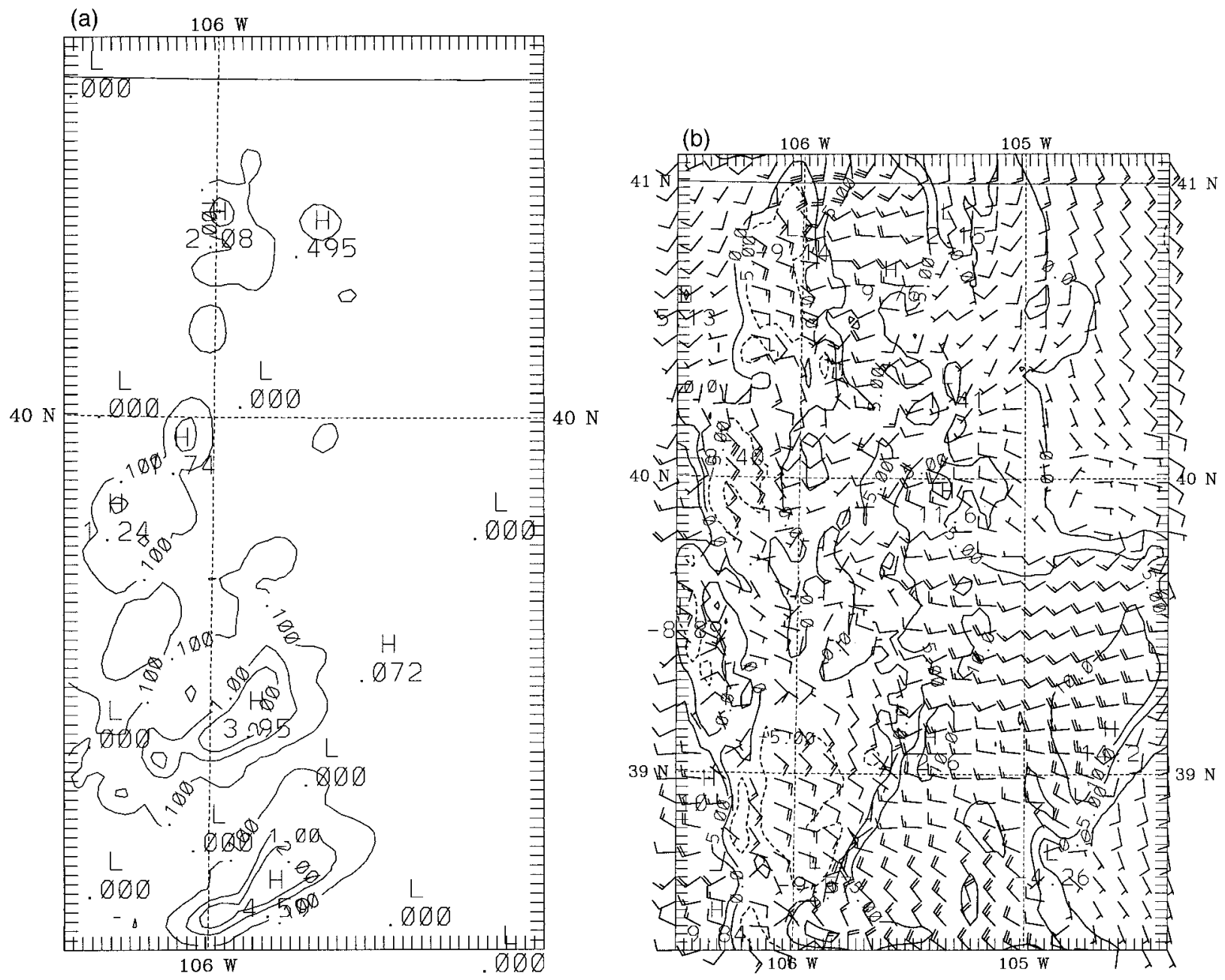

FIG. 14. (a) As in Fig. 8 for model simulation that does not include the effects of ice sedimentation (NOSED). (b) As in Fig. 9 except for the simulation NOSED.

vection can be made from radar reflectivity. The estimates are made from the relation $Z=300 R^{1.5}$, where $Z$ is the intensity of backscattered radiation detected by the radar and $R$ is the rainfall in $\mathrm{mm}$. In spite of the solid appearance of the convective line, radar-derived estimates of the precipitation show that it has a large horizontal variability (Fig. 19). Clearly, some of this variability cannot be captured in a model with horizontal resolution of $3 \mathrm{~km}$. Also, considering that the boundary layer is fairly dry, the radar may indicate small amounts of rain in areas where none actually reached the ground. Thus, it is not surprising that despite the relatively high density of hourly precipitation observations in this region, relatively few stations actually recorded any precipitation. Nevertheless, even with evaporation and error in radar estimates, they make it clear that several small areas received over $25 \mathrm{~mm}$ of precipitation. Given the fine scale and large gradients in the precipitation field the amounts of model precipitation are reasonable.

The low-resolution (LOWRES) simulation is in some ways clearer in its representation of the convective line (Fig. 20). It initiated the line and although it is somewhat to the west of the MCS on radar its boundaries are delineated well. It propagates the line strongly northward but more weakly to the east. It also represented the relative lack of precipitation between the mountains and the convergence line better than the control simulation. Although the LOWRES simulation had difficulty representing all the mountain convection, it did capture one convective region well, namely, the one that generated the outflow crucial to the initiation of the MCS. Thus, it is able to capture the initiation of the MCS, although it has problems with the system's later propagation. We believe this circumstance to be a propitious one and that a lower-resolution simulation would not be better than a higher-resolution one in all circumstances. The high-resolution simulation did a much better job overall of representing the mountain convection. To properly generate the MCS, the high-resolution model would have to reproduce the relative strength of the 


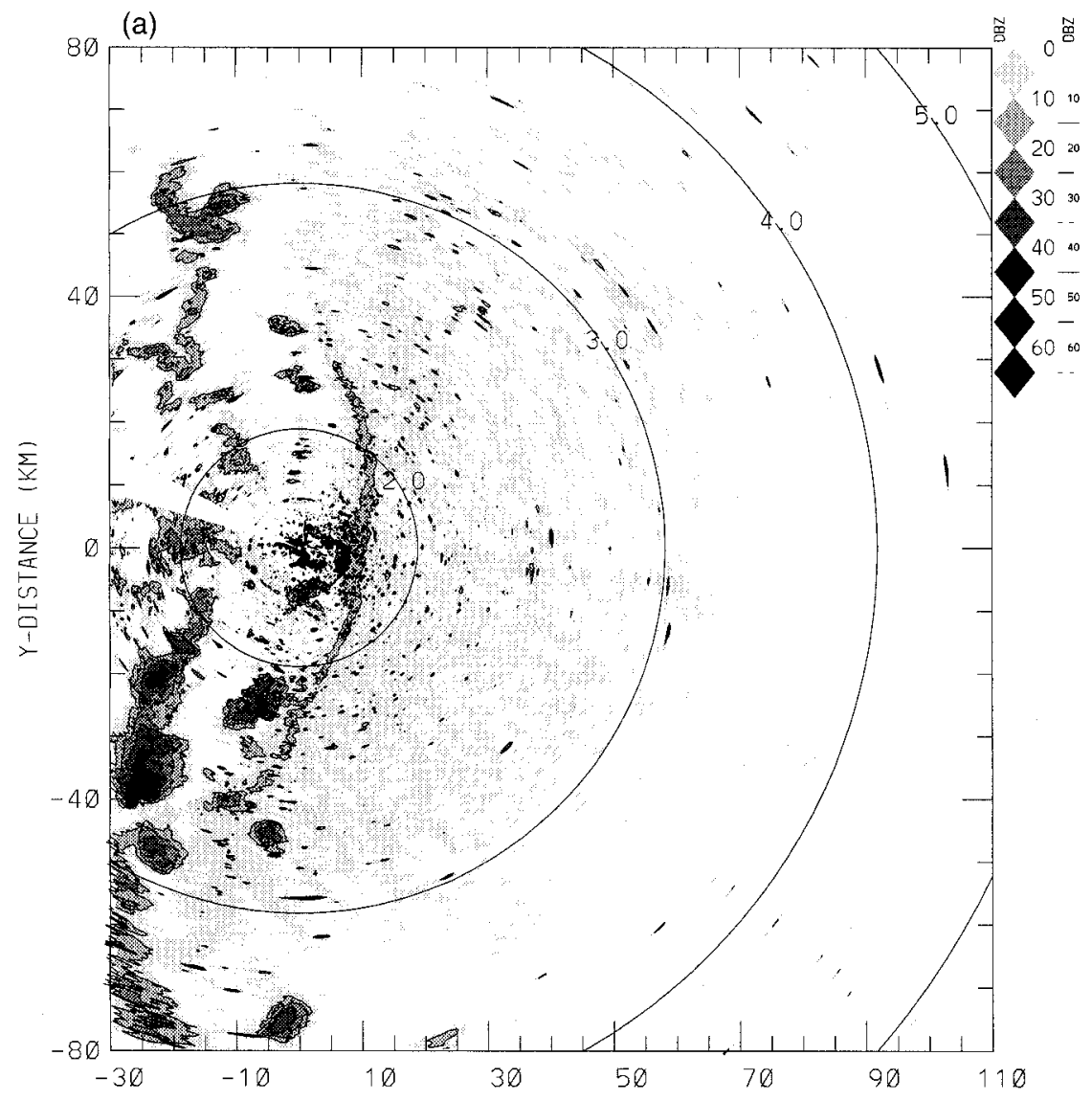

FIG. 15. Reflectivity from MHR at an elevation of $1.2^{\circ}$ in the plains domain: (a) 1954 UTC, (b) 2054 UTC.

outflow from several different cells. Any errors that occur in this simulation will result in errors in the location and/or strength of the resulting MCS. Although an MCS is generated in the high-resolution simulation, the representation of its initiation is not as well defined as in the low-resolution simulation. Thus, the control simulation gave a better representation of the model convection than the LOWRES simulation but the LOWRES simulation better delineated the initiation of the MCS. Although we recognize that the present comparisons with the radar are subjective ones, it is evident that at least in this case increasing the resolution of the numerical model did not yield a better representation of the MCS.

It could be argued that since a convergence line was already present that the outflow from the mountain convection was not needed to trigger the initiation of the MCS and its arrival just prior to the development of the convective line on the plains was just a coincidence. It has already been shown that without evaporative cooling the outflow from the mountain convection is almost nonexistent. In the NOEVAPCOOL simulation, at the time the model with full physics showed the initiation of the convective line, there is very little convection in the region of the convergence line (Fig. 21). Thus, the model provides evidence that the initiation of the convective line required the trigger provided by the outflow from the mountain convection.

Since the MCS is generated from the outflow of the mountain thunderstorms, factors that affect the production of this outflow also affect the subsequent initiation of the MCS. In the previous section, it was demonstrated that turning off cloud shading increased the intensity of the outflow. In the NOCLOUD simulation precipitation falls continuously as the outflow progresses from the mountains to the plains (Fig. 22). In reality the radar indicates that there were only small, isolated cells of precipitation in the area immediately adjacent to the mountains. The model indicates that the stronger outflow in the NOCLOUD simulation is able to generate precipitating cells in the region between the mountains and the convergence line. Thus, the presence of the region with little precipitation between the mountains and the convective line can, in this case, be attributed to the effects of the cloud shading, which decrease the intensity of the outflow from the mountain convection. These results would indicate that the ability of mountain thunderstorms to generate outflow of sufficient strength 


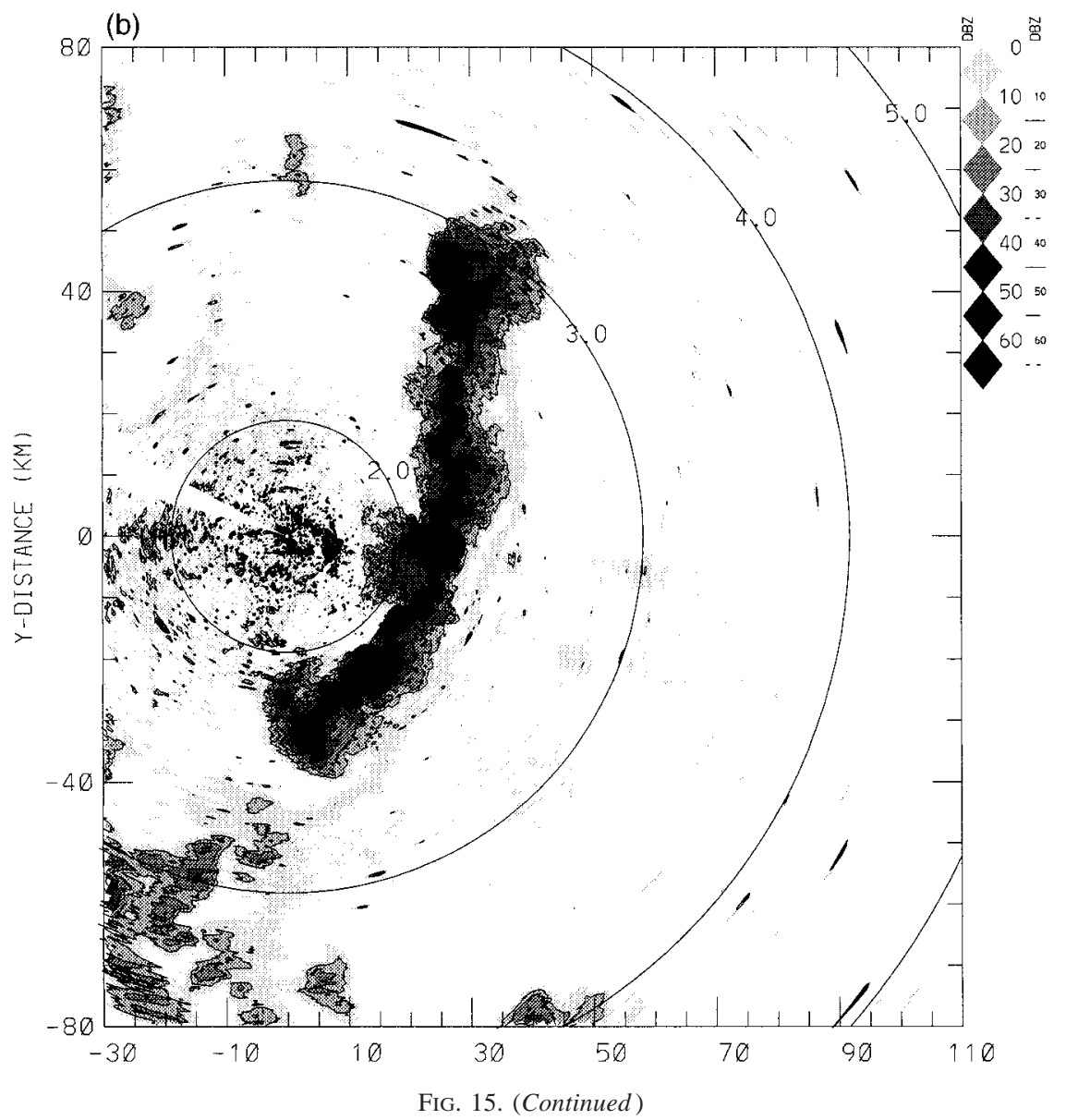

to initiate an MCS is controlled by the strength of those thunderstorms, which is in turn sensitive to the amount of solar radiation reaching the earth's surface. Once the convective line is generated, its development over the next couple of hours is not influenced substantially by the radiative effects of clouds.

The ice sedimentation process also discussed in the previous section has a more dramatic effect on the development of the convective line over the plains. In the NOSED simulation the outflow from the mountain storms is too weak to generate the convective line at the point where it was observed (Fig. 23). The outflow continues farther out on the plains and only generates some weaker convection farther east. The dry zone between the mountain and plains convection is increased in area and the overall precipitation amounts are smaller. Thus, the falling ice crystals act as an important source of precipitation particles and strongly influence not only mountain convection but also the MCS over the plains.

\section{Conclusions}

The initiation of the MCS studied in this case is dependent upon the outflow generated by mountain convection. Thus the ability of the model to simulate the
MCS initiation is dependent on its success in properly representing the mountain convection and its outflow. In this case a lower-resolution model was able to simulate the initiation of the MCS because it was able to produce the mountain convection from which it evolved. Other areas of mountain convection were not as well represented by the lower-resolution model and it would not be surprising if this model setup did not produce results that were superior to those of the high-resolution model for other cases. The lower-resolution model also had difficulty simulating the eastward (but not the northward) propagation of the convective line. These results indicate that simply decreasing the grid size of a numerical model will not always yield a better representation of convective activity.

The outflow from the mountain convection is necessary for the formation of the MCS in this case although the surface convergence line does provide a focus for the process. To initiate the convective line the model not only has to properly represent the location of the mountain convection but also the strength of its outflow. A number of convective cells existed along the front range of the Rocky Mountains on 21 June 1993, but only a minority had outflow strong enough to generate subsequent convection. Our results indicate that a 

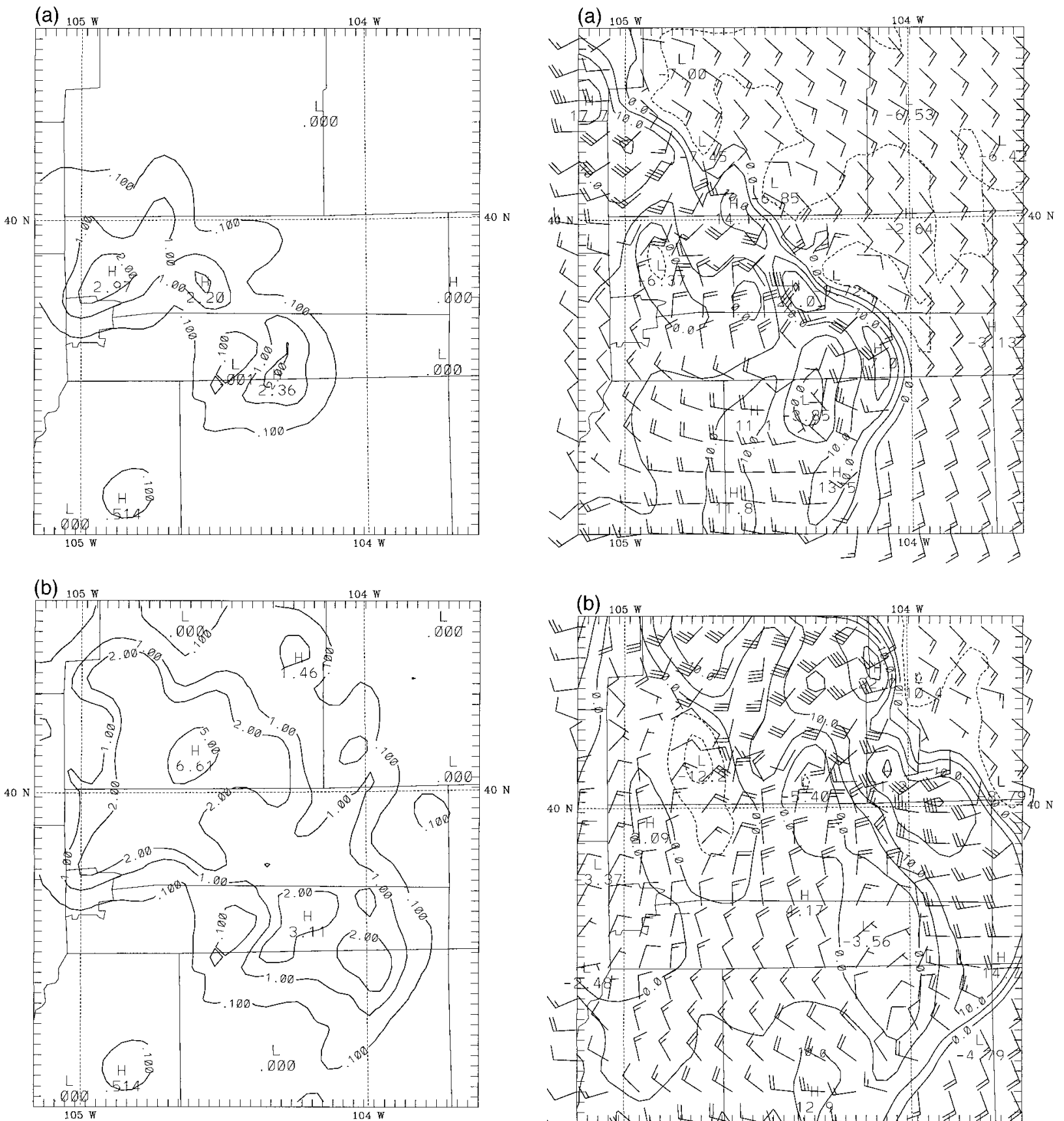

FIG. 16. Precipitation accumulation for the control experiment through (a) 2100 UTC, (b) 2200 UTC. Contours are at 0.1, 1.0, 2.0, 5.0 , and $10.0 \mathrm{~mm}$. Domain is the same as that of the radar image in Fig. 15.

fairly high-resolution model would be needed to represent all the mountain convective activity. In some cases (but not this one) such a high-resolution model might also be required to initiate an MCS.

A tight link between the outflow from mountain convection and MCS generation has several implications. Convective activity in the Rocky Mountains occurs almost every day during the summer. Thus, this region

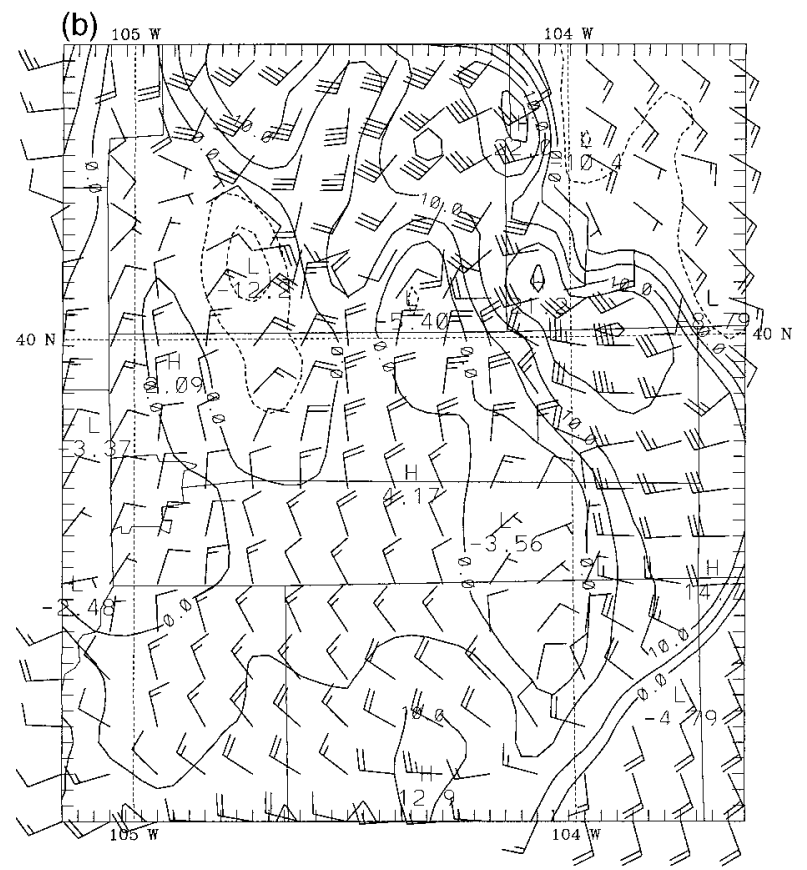

FIG. 17. As in Fig. 9, winds in the control experiment over the plains domain valid (a) 2100 UTC, (b) 2200 UTC.

has an abundant supply of such outflow and would be a favorable one for MCS development. It would also be expected, however, that MCSs should form downwind of mountain convection. Mountain convective activity has preferred regions in which to form that vary somewhat with the prevailing winds (Banta and Schaaf 1987). It would follow then that MCSs would have corresponding climatologically preferred locations in 


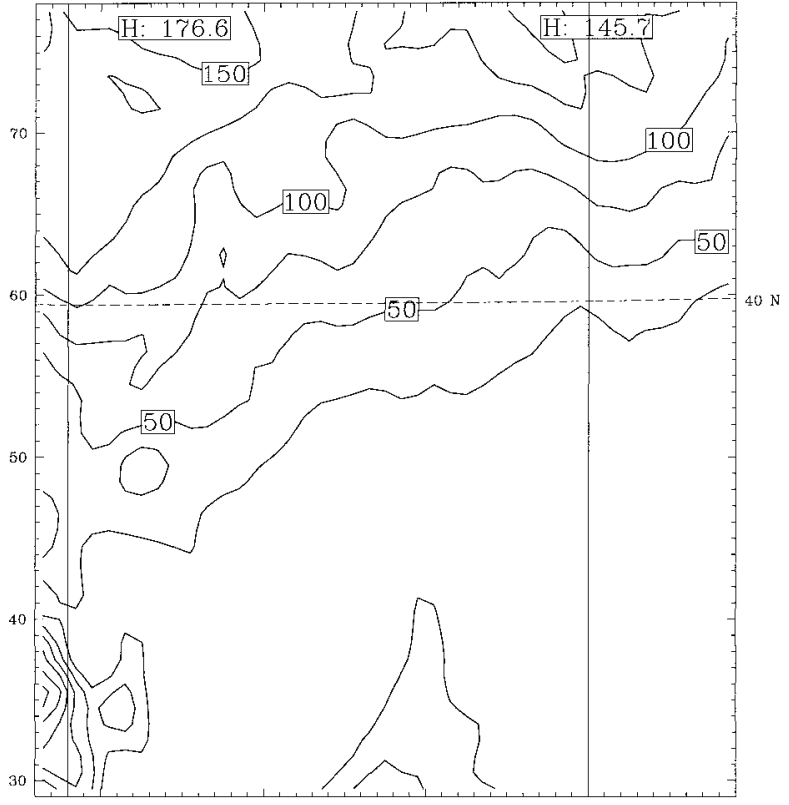

FIG. 18. Model forecast convective inhibition (CIN) valid 1800 UTC 21 Jun 1993. Contours are drawn every $25 \mathrm{~J} \mathrm{~kg}^{-1}$. Domain is the same as for the precipitation fields in Fig. 16.

which to form and this issue needs to be investigated further.

Processes that affect the character of the mountain convection would also influence subsequent MCS initiation. In this paper we have shown that the influence of clouds on radiation and the surface energy budget

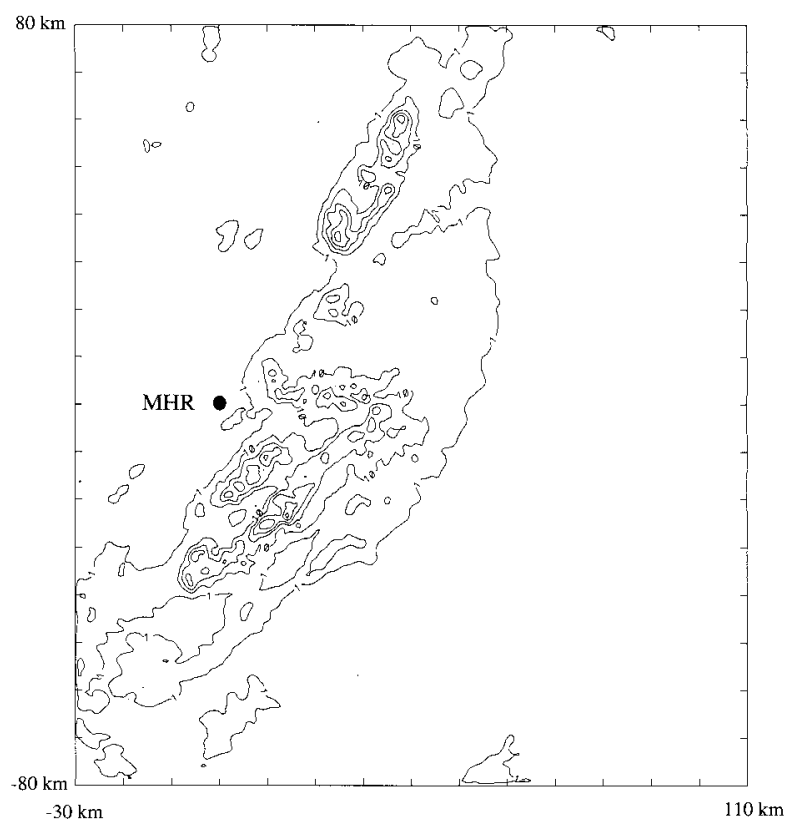

FIG. 19. Estimated precipitation amounts from MHR for the period 2000-2200 UTC 21 Jun 1993 using the relation $Z=300 R^{1.5}$. Contours are at $1,10,20,30$, and $40 \mathrm{~mm}$.
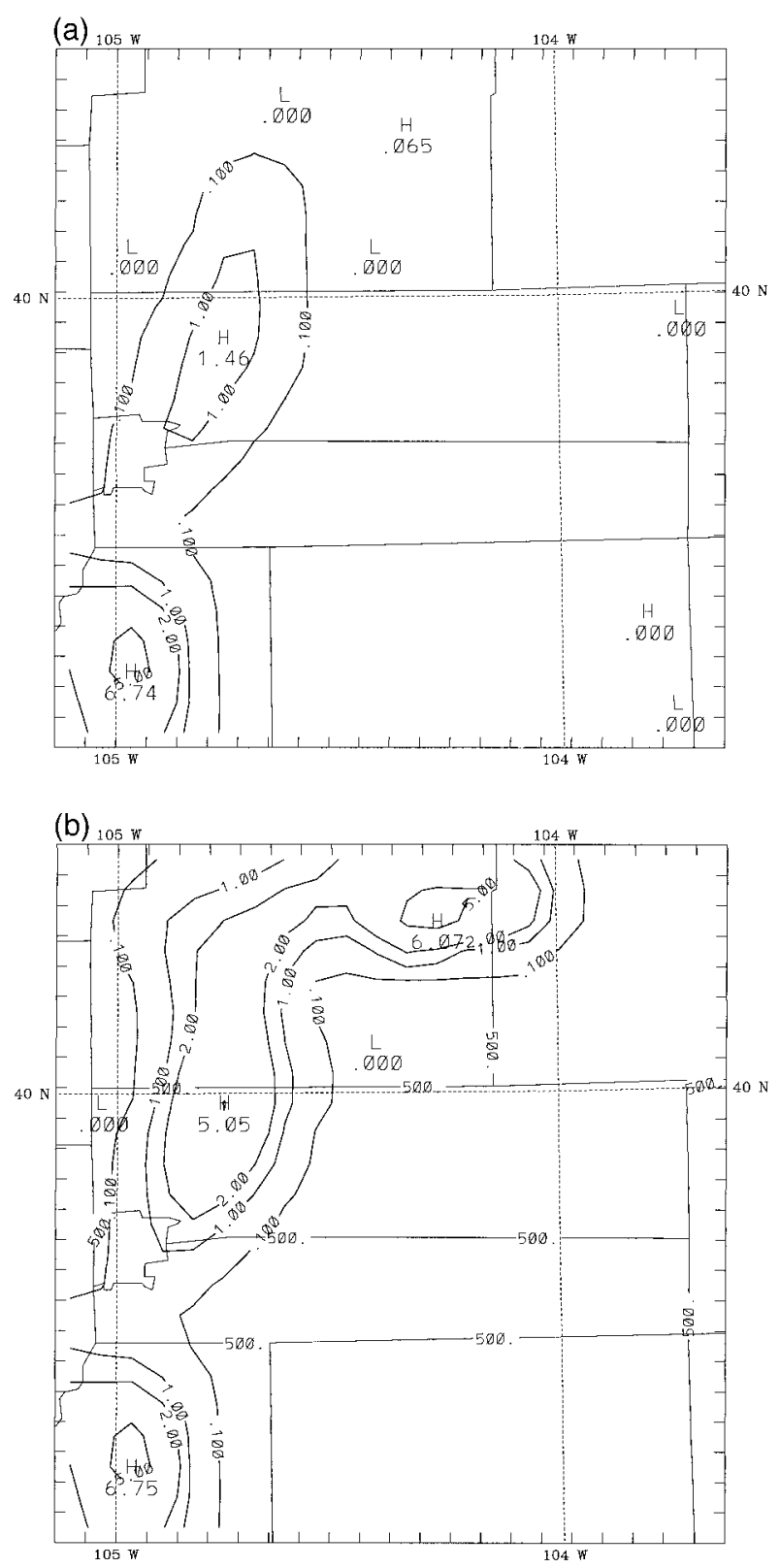

FIG. 20. Precipitation accumulation from experiment LOWRES through (a) 2100 UTC, and (b) 2200 UTC. Contours are at 0.1, 1.0, 2.0 , and $5.0 \mathrm{~mm}$. Domain is the same as that of the radar image in Fig. 15.

can reduce the intensity of convective activity and its subsequent outflow. Unfortunately, cloud cover is a difficult variable to predict with a numerical model and this sensitivity points to continued problems with forecasting such systems with these models until predictions of cloud cover are improved. Ice processes and in particular ice sedimentation exerted a considerable influence on the strength of the outflow from the mountain convection. This sensitivity shows the importance of the moisture field in the middle to upper troposphere in the development of the MCS. 


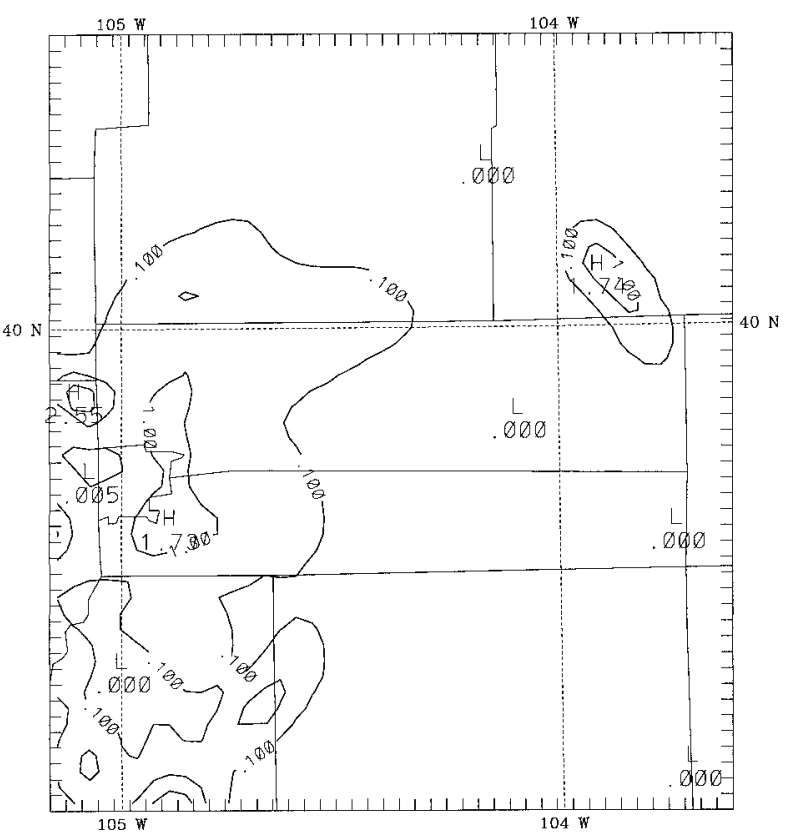

FIG. 21. Model-accumulated precipitation through 2100 UTC for simulation without evaporative cooling (NOEVAPCOOL). Contours are at $0.1,1.0,2.0,5.0$, and $10.0 \mathrm{~mm}$.

Since the development of an MCS can be dependent on the presence of strong outflow from previous convection, and since all the mountain thunderstorms present did not produce outflow of the same strength, we need to know more about how thunderstorm outflow is

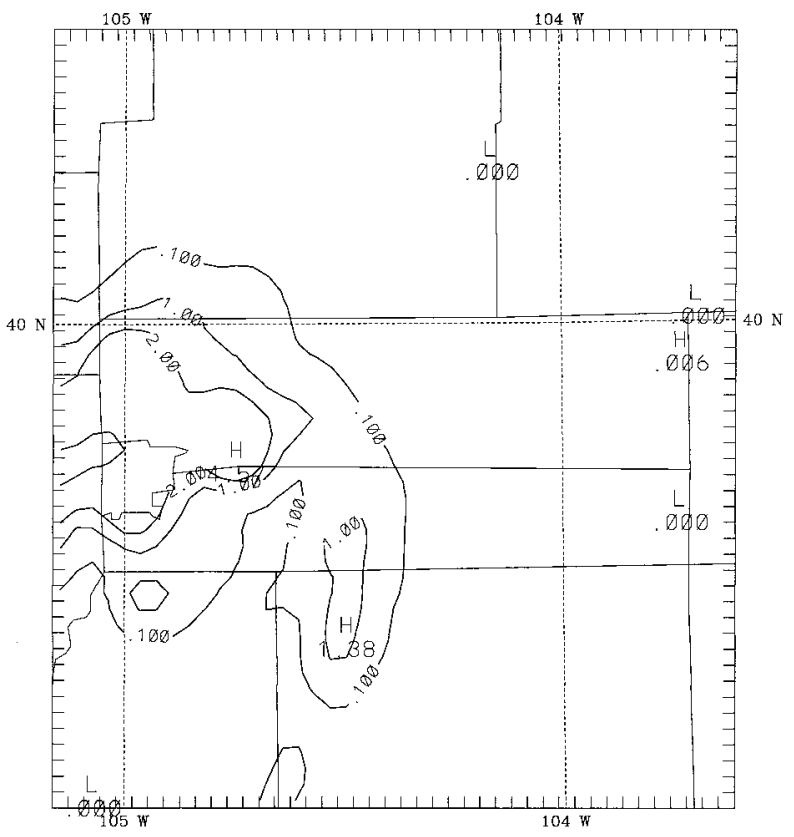

FIG. 22. Model-accumulated precipitation through 2100 UTC for simulation without the effects of clouds on radiation (NOCLOUD). Contours are at $0.1,1.0,2.0,5.0$, and $10.0 \mathrm{~mm}$.

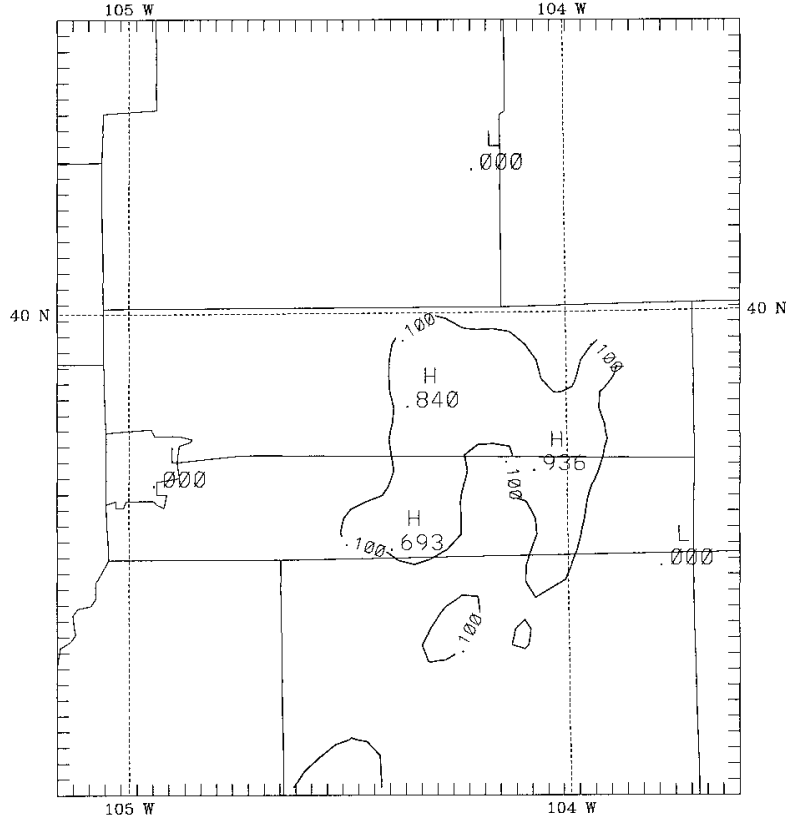

FIG. 23. Model-accumulated precipitation through 2100 UTC for simulation without ice sedimentation (NOSED). Contours are at 0.1 , $1.0,2.0,5.0$, and $10.0 \mathrm{~mm}$.

generated and why some cells generate more outflow than others. In the case we studied, outflow was stronger in the direction of the prevailing wind. The strength of the outflow could also be dependent on such factors as environmental wind shear and relative humidity distribution. The ability of the outflow to generate new convection, however, is not necessarily determined by its strength. Multicellular storms are favored in environments with moderate wind shear and it is possible for thunderstorm outflow to move too quickly to generate new cells (Weisman and Klemp 1982). In addition, the instability of the environment would strongly influence the possibility of developing more convective activity. Nonetheless, knowledge of the strength of thunderstorm outflow itself is important for a number of interests, such as aviation, construction, and agriculture, which are sensitive to strong low-level winds and wind shear. Therefore, factors that control the strength of the outflow itself are worthy of further investigation.

Certainly the forecasting of MCS initiation is a difficult task. We have shown some factors that were important for one case where an MCS developed as a result of outflow from mountain convective activity in a region where MCS initiation is especially favored. Further studies are needed to show which factors are important for MCS that initiate from other forcing mechanisms and in different parts of the world.

Acknowledgments. Some of the calculations in this work were performed with the Origin 2000 Supercomputer in the Kansas Center for Advanced Scientific Computing sponsored by the NSF-EPSCoR/K*STAR 
program. Computing was also done on the NCAR Cray Y/MP. This investigation was supported in part by the General Research Fund of the University of Kansas. Dr. Jimy Dudhia and other members of the MM5 support team provided many useful insights on the MM5 model.

\section{REFERENCES}

Augustine, J. A., and F. Caracena, 1994: Lower-tropospheric precursors to nocturnal MCS development over the central United States. Wea. Forecasting, 9, 116-135.

Banta, R. M., and C. L. B. Schaaf, 1987: Thunderstorm genesis zones in the Colorado Rocky Mountains as determined by traceback of geosynchronous satellite images. Mon. Wea. Rev., 115, 463476.

Blackadar, A. K., 1976: Modeling the nocturnal boundary layer. Preprints, Third Symp. on Atmospheric Turbulence and Air Quality, Raleigh, NC, Amer. Meteor. Soc., 46-49.

_ 1979: High resolution models of the planetary boundary layer. Advances in Environmental Science and Engineering, Vol. 1, J. R. Pfafflin and E. N. Ziegler, Eds., Gordon and Breach Science, $50-85$.

Cotton, W. R., R. L. George, P. J. Wetzel, and R. L. McAnelly, 1983: A long-lived mesoscale convective complex. Part I: The mountain-generated component. Mon. Wea. Rev., 111, 1893-1918.

Dudhia, J., 1993: A nonhydrostatic version of the Penn State-NCAR mesoscale model: Validation tests and simulation of an Atlantic cyclone and cold front. Mon. Wea. Rev., 121, 1493-1513.

Fritsch, J. M., R. J. Kane, and C. R. Chelius, 1986: The contribution of mesoscale convective weather systems to the warm-season precipitation in the United States. J. Climate Appl. Meteor., 25, $1333-1345$.

Grell, G. A., 1993: Prognostic evaluation of assumptions used by cumulus parameterizations. Mon. Wea. Rev., 121, 764-787.

Koch, S. E., 1984: The role of an apparent mesoscale frontogenetical circulation in squall line initiation. Mon. Wea. Rev., 112, 20902111.

Maddox, R. A., 1980: Mesoscale convective complexes. Bull. Amer. Meteor. Soc., 61, 1374-1387.

_- F. Canova, and L. R. Hoxit, 1980: Meteorological characteristics of flash flood events over the western United States. Mon. Wea. Rev., 108, 1866-1877.

McAnelly, R. L., and W. R. Cotton, 1986: Meso- $\beta$-scale characteristics of meso- $\alpha$-scale convective complexes. Mon. Wea. Rev., 114, 1740-1770.

Segal, M., J. F. W. Purdom, J. L. Song, R. A. Pielke, and Y. Mahrer, 1986: Evaluation of cloud shading effects on the generation and modification of mesoscale circulations. Mon. Wea. Rev., 114, 1201-1212.

Stensrud, D. J., and J. M. Fritsch, 1993: Mesoscale convective systems in weakly forced large-scale environments. Part I: Observations. Mon. Wea. Rev., 121, 3326-3344.

— , and — 1994: Mesoscale convective systems in weakly forced large-scale environments. Part II: Generation of a mesoscale initial condition. Mon. Wea. Rev., 122, 2068-2083.

Szoke, E. J., and J. A. Augustine, 1990: An examination of the mean flow and thermodynamic characteristics of a mesoscale flow feature: The Denver Cyclone. Preprints, Fourth Conf. on Mesoscale Processes, Boulder, CO, Amer. Meteor. Soc., J17-J18.

—, M. L. Weisman, J. M. Brown, F. Caracena, and T. W. Schlatter, 1984: A subsynoptic analysis of the Denver tornadoes of 3 June 1981. Mon. Wea. Rev., 112, 790-808.

Tripoli, G. J., and W. R. Cotton, 1989: Numerical study of an observed orogenic mesoscale convective system. Part 1: Simulated genesis and comparison with observations. Mon. Wea. Rev., 117, 273304.

Weisman, M. L., and J. B. Klemp, 1982: The dependence of numerically simulated convective storms on vertical wind shear and buoyancy. Mon. Wea. Rev., 110, 504-520.

— W. C. Skamarock, and J. B. Klemp, 1997: The resolution dependence of explicitly modeled convective systems. Mon. Wea. Rev., 125, 527-548.

Zhang, D. L., and R. A. Anthes, 1982: A high-resolution model of the planetary boundary layer-Sensitivity tests and comparisons with SESAME-79 data. J. Appl. Meteor., 21, 1594-1609. 